\title{
Optimization of Combustion Characteristics of Diesel Engine Fueled by Biofuels and Its Diesel Blends with Additive Titanium Dioxide Nano-Particles
}

\author{
Jacob S*, Karikalan L \\ Department of Automobile Engineering, VELS Institute of Science, Technology \& Advanced Studies (VISTAS), Pallavaram, \\ Chennai, Tamil Nadu 600 117, India
}

Corresponding Author Email: jacobthermal@gmail.com

https://doi.org/10.18280/ijht.390636

Received: 2 December 2021

Accepted: 27 December 2021

\section{Keywords:}

biofuel, jatropha methyl ester, CFD, mahua methyl ester, Kirloskar, combustion, emission characteristics, optimization

\begin{abstract}
The fuel crisis throughout the world made many countries to be aware of their vulnerability to oil shortages. So many researches are still in progress and focus on the growth of bio fuel usage. In this regard, alternative fuels and the drivetrain play a major rule in critical emission issues. However, at the same time, enormous and vast number of vehicles have started to claim and place their heavy demand for alternative sources of fuel. Of course, gasoline and diesel, the conventional fuels will become scarce and much costlier. With a present known reserves and steep rise of demand and rate of consumption, hope of crude oil import is not going to last long. The CFD investigation is to find the combustion characteristics of the BioFuel with the various compositions of mixing with diesel, the Kirloskar IC Engine is taken for this research and the results of pressure, velocity, turbulence kinetic energy, temperature gradients, fuel combustions, oxidizers volume fractions also obtained from the CFD analysis results. CFD Analysis of Biodiesel combustion done in ANSYS Fluent. Software modeling of IC Engine done in CATIA V5 Software. Jatropha Methyl Ester (JME) and Mahua Methyl Ester (MME) are used for this research. Combustion characteristics in addition to emission parameters are assessed then a conclusion can be drawn.
\end{abstract}

\section{INTRODUCTION}

The transport vehicle population is still in increase over the past decade. Environmental problem and degradation are an ever-remaining problem for the outcome of enormous growth in motor vehicle population [1-3]. This issue directly and indirectly raises the urgent need of suitable alternative fuels. Unlike other developed countries, India is happened to be a diesel-based economy [4, 5]. It is an alarming signal that oil production is supposed to reach a peak beyond 2016 and from there on, it is estimated to eventually decrease ever. So, it is a clear fact that without some other appropriate alternative fuels, mankind will experience to sustain eco-mobility in the future $[6,7]$. Diesel engines are utilized generally throughout the world as power plants for different purposes because of their incredible drivability and economy. However, they are likewise the significant supporters of air toxins like CO, NOx, $\mathrm{CO}_{2}$, and other harmful mixtures. Venkateswara Rao [8] and Sureshkumar et al. [9] simultaneously the worldwide fuel emergencies and expansion in fuel costs have driven us to the need of building up another fuel that would answer these issues [10-12]. For about 10 years explores and examinations were directed on the utilization of ethanol-diesel mix as a fuel in the diesel engine. Numerous recommendations were made and few analyses were executed. A considerable outcome arrives at a resolution that ethanol diesel mix could take care of the issues referenced previously [13-16]. The point of this task is to track down the ideal ethanol-diesel mix that suits the diesel engine. With the assistance of different techniques to discover fuel properties, execution tests on diesel engines for different fuel mixes, and programming investigation the ideal mix is discovered [17-19]. Niemi et al. [20, 21] had led execution in a diesel engine utilizing mustard seed oil. The engine brake power with mustard seed oil was practically equivalent to that of diesel fuel oil (DFO). The BTE was estimated at $41 \%$ for diesel fuel and $40 \%$ for mustard seed oil. The utilization of mustard seed oil diminished the fumes smoke and NOx emanations. Neither did the fumes of HC emanations decide to utilize an FT-IR analyzer nor did the engine exhibition uncover any huge contrast between mustard seed oil and the diesel fuel. The force of the engine energized with mustard seed oil was 5\% lower than diesel. Radu and Mircea [22] examined engine yield power, force, fuel utilization, and so on in a diesel engine for sunflower oil and a blend containing half sunflower oil and half diesel fuel. The presentation of the engine was resolved through direct estimation. The yield power decreased by $37 \%$ for flawless sunflower oil. This decrease in power was because of lower burning warmth, higher thickness, and the diverse conduct of the infusion gear. The abatement of the mean pace of infusion diminished the engine commotion. The vegetable oil-diesel oil blend appeared to be a superior option in contrast to unadulterated oils. The expansion in the engine force utilizing this combination forced changes in the infusion timing [23-25]. Graef et al. directed a test on diesel engine with arranged biodiesel powers from feedstocks with adjusted syntheses including the methyl esters of low palmitic soybean oil, a halfway trans esterified soybean oil, an engineered mix of immersed esters were mixed with No.2 diesel in $20 \%$, half focuses [26]. They showed that the engine exhibition and 
burning cycle of the relative multitude of mixes were practically like No.2 diesel fuel, with $13 \%$ higher fuel utilization and a more limited start delay. Decreases in CO, HC, absolute particulate and 5.2\% expansion NOx were likewise observed [27-30].

\section{EXPERIMENTAL ANALYSIS OF JATROPHA AND MAHUA OIL BIODIESEL}

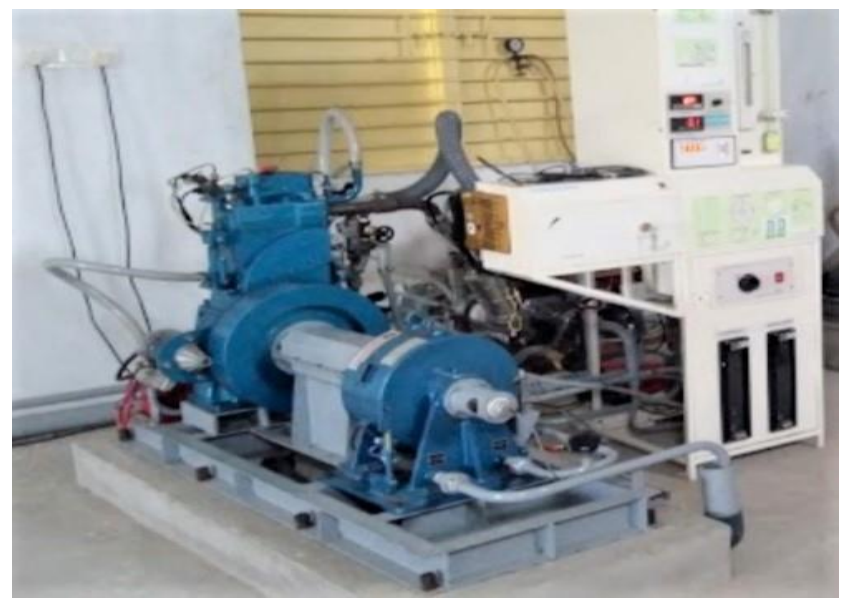

Figure 1. Experimental setup

Table 1. Properties of fuel

\begin{tabular}{ccccc}
\hline Properties & \multicolumn{4}{c}{ DieselJMEMMEJME\&MME } \\
\hline Density kg/m & 820 & 834 & 835 & 835 \\
Viscosity & 2.8 & 3.17 & 3.14 & 3.12 \\
@ 400C CST & & & & \\
Calorific value MJ $/ \mathrm{kg}$ & 42.5 & 41.1941 .20 & 41.22 \\
Flashpoint ${ }^{\circ} \mathrm{C}$ & 57 & 70 & 71 & 68 \\
Fire point ${ }^{\circ} \mathrm{C}$ & 67 & 79 & 77 & 76 \\
\hline
\end{tabular}

Ball processing is the technique for the creation of nano materials additives for biodiesel. This measure is utilized in the creation of metallic and artistic nano materials. These plants are outfitted with a crushing medium made out of carbide or steel. Ball milling factories turn in an even pivot incompletely loaded up with material to be grounded in addition to the pounding medium. In this research powdered Titanium dioxide material is used as an additive with biodiesel. The biodiesel is prepared by blending the titanium dioxide additives in the manual methyl ester with the help of a Sonicator system. The sonicator function is to stir the nanoadditives in biodiesel (mahua methyl ester). Trials were directed in Single cylinder Kirlosker computerized CI Engine as shown in Figure 1. with dissimilar biofuels mixes of JME (Jatropha Methyl Ester) and Mahua Methyl Ester (MME). The investigations on direct injection, single-cylinder, compression Ignition engine at various injection pressure utilizing different blends. A $5 \mathrm{HP}(3.5 \mathrm{~kW})$ four-stroke C.I engine as shown in Figure 1 is picked to examine the performance and combustion characteristics. The airstream rate into the engine is estimated with the help of mass stream sensors and fuel utilization is estimated using the burette technique. Sensors were used to gather, store and analyze the information by computerized information obtaining systems
(IC engines). Different sensors were used during the trial of the engine. Loading was applied to the engine and the test was conducted at various loads. The EGR is used to measure Nitrogen Oxide (ppm), CO (Carbon mono oxide) (\% vol), Unburnt Hydrocarbon (ppm), Carbon dioxide (\%) radiation in the vapor. Table 1 shows the properties of different blends.

\section{METHODOLOGY}

The test information on variable compression ratio diesel engines is methodically examined. The impact of blend proportion and fuel injection pressure at a CR of 17.5 has been analyzed by different load conditions. Three blends properties have been compared with diesel to comprehend the impact of every condition. The performance of the VCR (Variable Compression Ratio) diesel engine was discovered to be smooth everywhere on the full load condition at various pressure, compression Ratio (CR17.5:1) with no operative challenges for dual biodiesel mix diesel fuel. The IC engine BTE (Brake thermal efficiency) is the proportion of the thermal power in fuel to the energy conveyed by the engine at the driving rod. It significantly relies upon the way where the energy is changed over as the productivity is standardized concerning the fuel calorific value. The brake thermal efficiency shows the capacity of the combustion system to get the exploratory fuel and offers equivalent methods for evaluating how proficient the energy in the fuel can be changed into mechanical yield.

\section{MATHEMATICAL MODELING OPTIMIZATION}

Figure 2 shows the 2-D model of the CI Engine with its specifications. Figure 3 shows the 3-D model of CI Engine to be analyzed in Ansys software.Figure 3 shows the mesh model of the CI engine to be analyzed with biodiesel in ANSYS Fluent Software.

The analysis is carried out in Ansys fluent software and the output result is compared through the optimization method.

The mesh model of the Kirloskar Diesel Engine is taken for analyzingStatic pressure contours, Static Temperature Contours, Mass Fraction Contours of $\mathrm{CO}_{2}$, Mass Fraction Contours of $\mathrm{N}_{2}$, Mass Fraction Contours of $\mathrm{H}_{2} \mathrm{O}$, Mass Fraction of $\mathrm{O}_{2}$ of Combustion ofJME (Jatropha Methyl Ester) and Mahua Methyl Ester (MME).

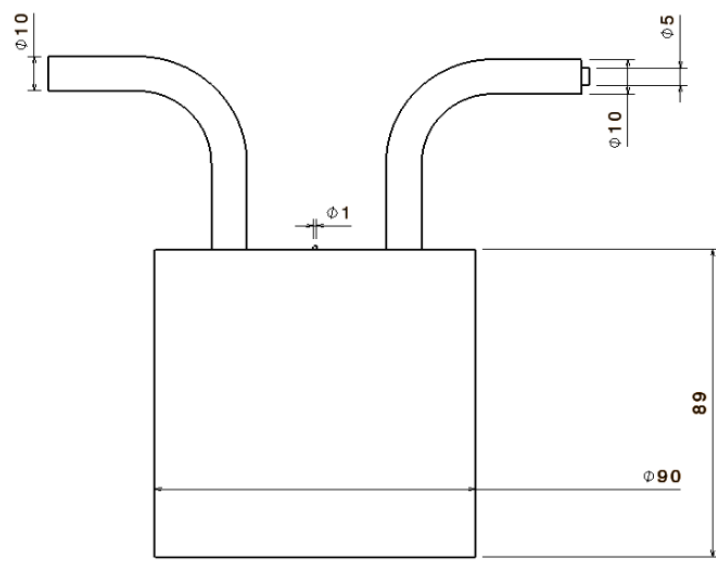

Figure 2. 2-D Model of IC engine 


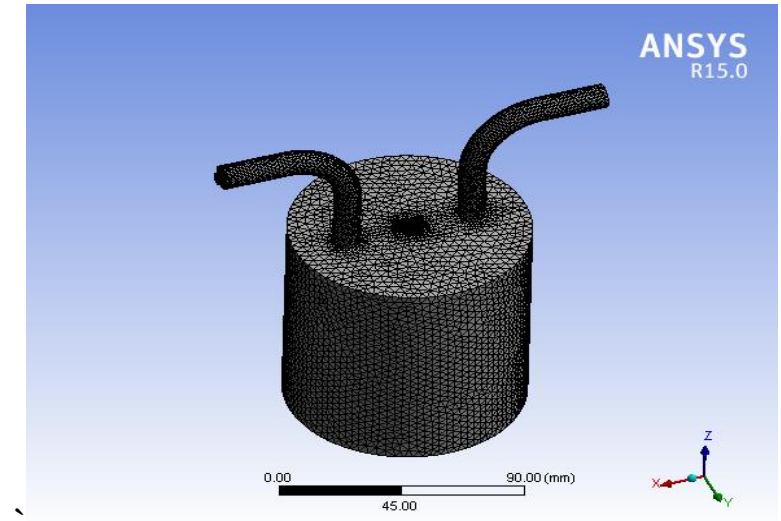

Figure 3. Mesh model of IC engine

\subsection{Analysis of JME and MME biodiesel}

The modeled CI engine is analyzed using ANSYS FLUENT as shown in Figure 4 to simulate the combustion and thermal flow and to determine static pressure contours of combustion with Jatropha Methyl Ester (JME) and Mahua Methyl Ester (MME) as a biofuel.The input values are fed to the software for analysis.

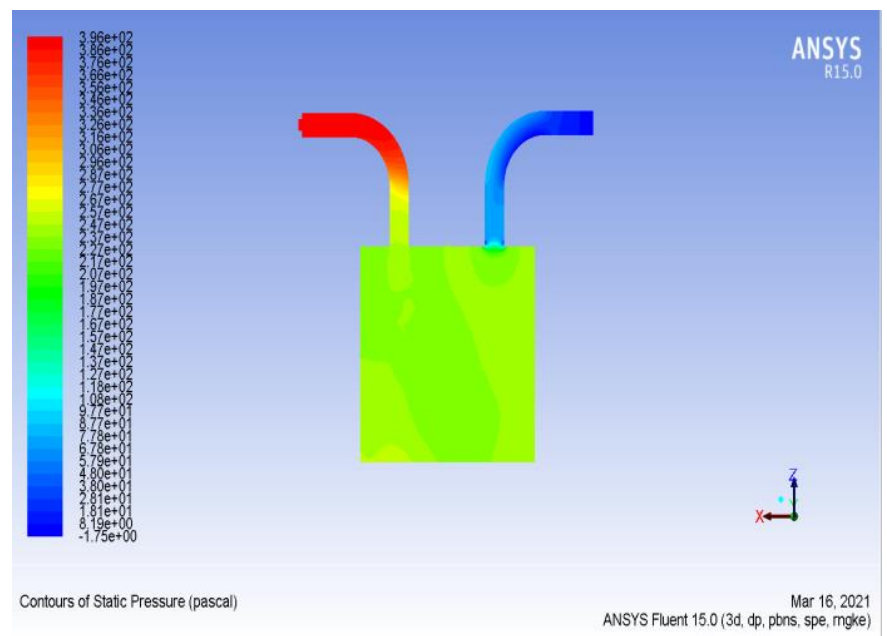

Figure 4. Static pressure contours of combustion JME

\section{STATIC PRESSURE}

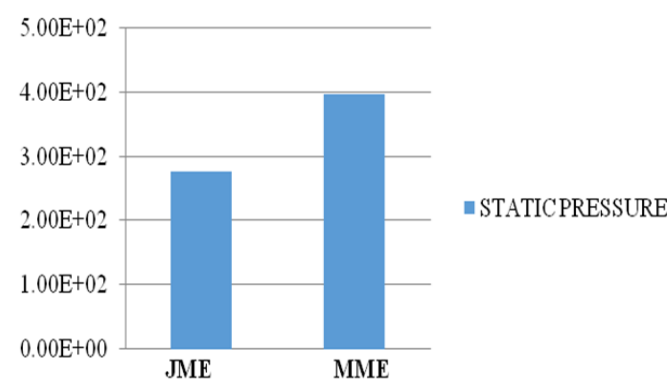

Figure 5. Values of the static pressure of combustion JME and MME

The output graph as shown in Figure 5 is plotted with the values obtained from the above analysis of static pressure contours of combustion of Jatropha Methyl Ester (JME) and Mahua Methyl Ester (MME) using Ansys Fluent. From the overall comparison,Mahua Methyl Ester (MME) biodiesel gives better results for static pressure around 400 Pascal.

\subsection{Static temperature analysis}

Figure 6 shows the output of static temperature contours of combustion of Jatropha Methyl Ester (JME) and Mahua Methyl Ester (MME) with the aid of Ansys. The red contour denotes the highest temperature region and the blue contour denotes the minimum temperature region.Temperature is measured in units of Kelvin. Mahua Methyl Ester biodiesel gives better results for static temperature of $2250 \mathrm{~K}$ compared to Jatropha Methyl Ester results for $1400 \mathrm{~K}$.

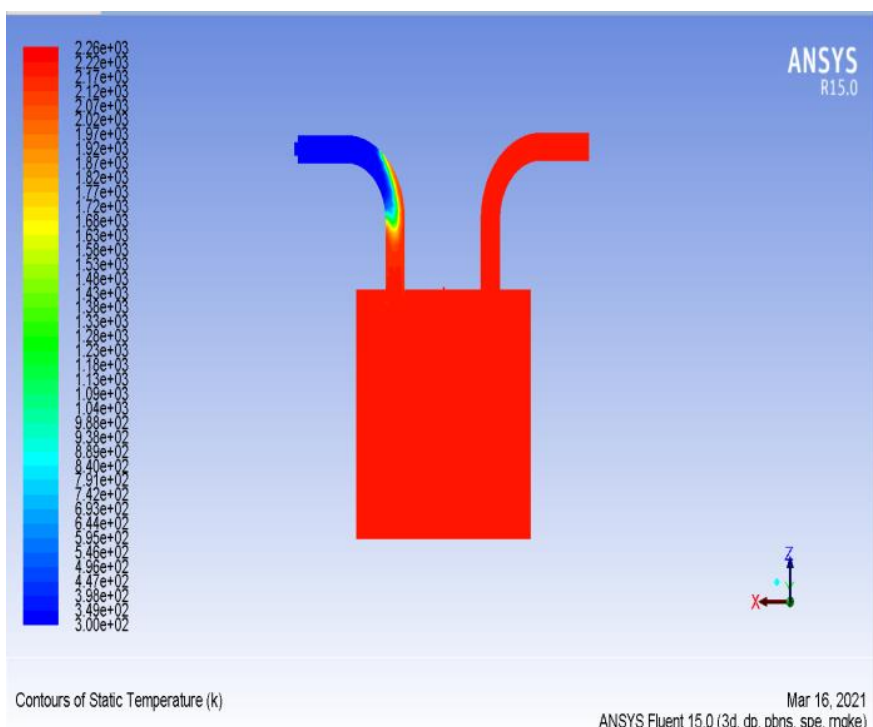

Figure 6. Static temperature contours of combustion MME

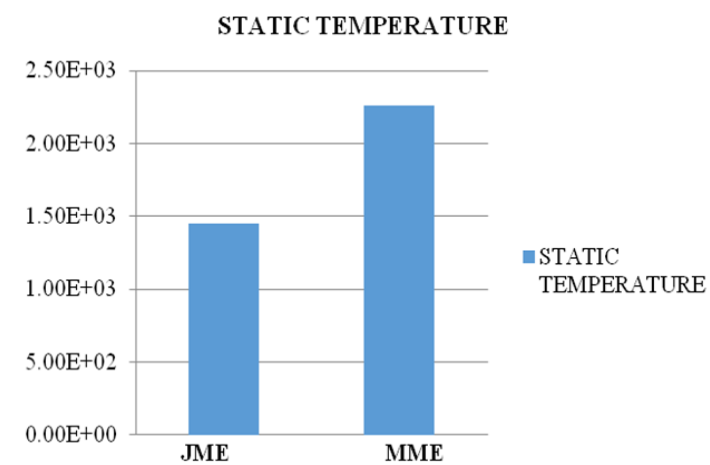

Figure 7. Values of static temperature of combustion JME and MME

The output graph as shown in Figure 7 is plotted with the values obtained from the above analysis of static temperature contours of combustion of Jatropha Methyl Ester (JME) and Mahua Methyl Ester (MME) using Ansys Fluent. Fromthe overall comparison,Mahua Methyl Ester (MME) biodiesel gives the best results in static temperature compared to Jatropha Methyl Ester (JME).

\subsection{Mass fraction of $\mathrm{CO}_{2}$ analysis}

The mass fraction of $\mathrm{CO}_{2}$ emission in $\mathrm{CI}$ Engine is analyzed with two different biodiesel i.e Jatropha Methyl Ester (JME) and Mahua Methyl Ester (MME) as displayed in the Figure 8.The analysis is done using Ansys software.The yellow contour indicates average emission and red contours indicate 
the maximum $\mathrm{CO}_{2}$ emissions. Jatropha Methyl Ester gives less $\mathrm{CO}_{2}$ emissions of 0.2 parts per million (ppm) compared to Mahua Methyl Ester (MME).

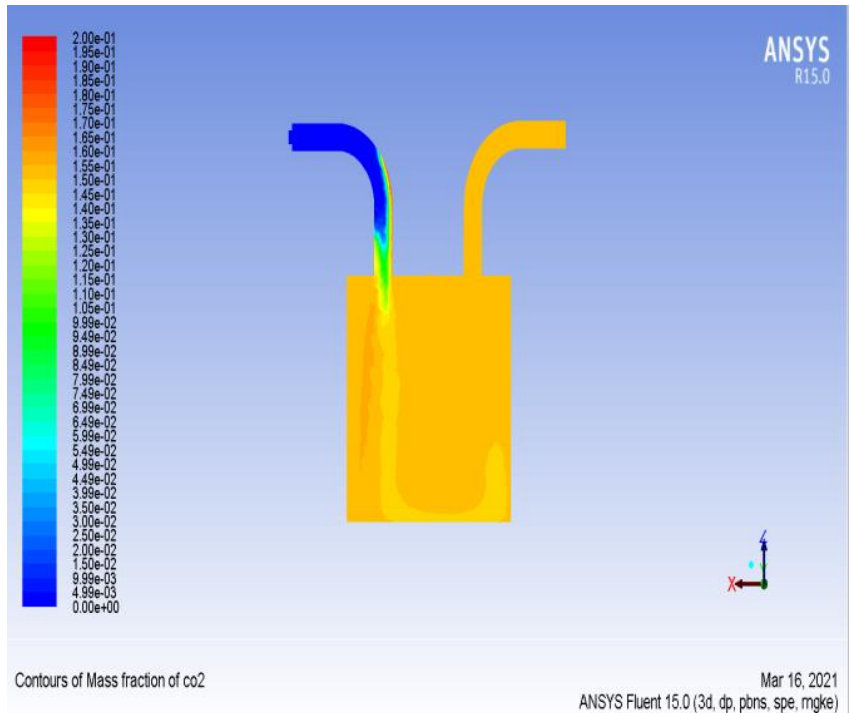

Figure 8. Mass fraction contours of $\mathrm{CO}_{2}$ of combustion JME

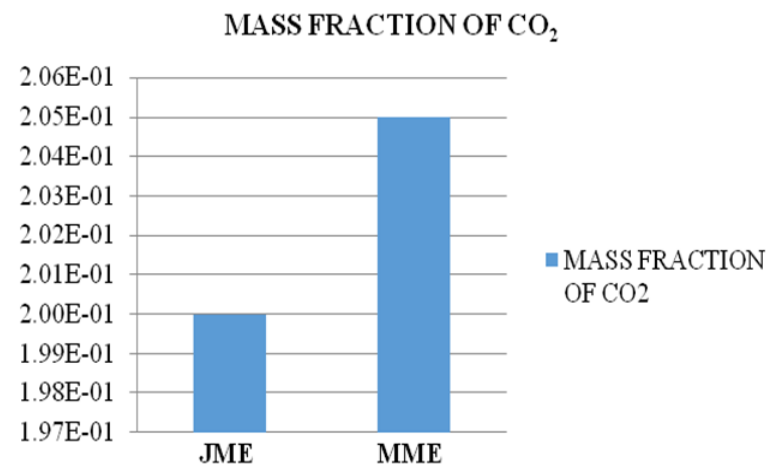

Figure 9. Values of mass fraction of $\mathrm{CO}_{2}$ of combustion JME and MME

The output graph is plotted with the values obtained from the above analysis of mass fraction contours of $\mathrm{CO}_{2}$ of combustion of Jatropha Methyl Ester (JME) and Mahua Methyl Ester (MME) using Ansys Fluent as displayed in Figure 9. From the overall comparison,Jatropha Methyl Ester (JME) biodiesel gives less $\mathrm{CO}_{2}$ emission compared to Mahua Methyl Ester (MME).

MASS FRACTION OF $\mathrm{N}_{2}$

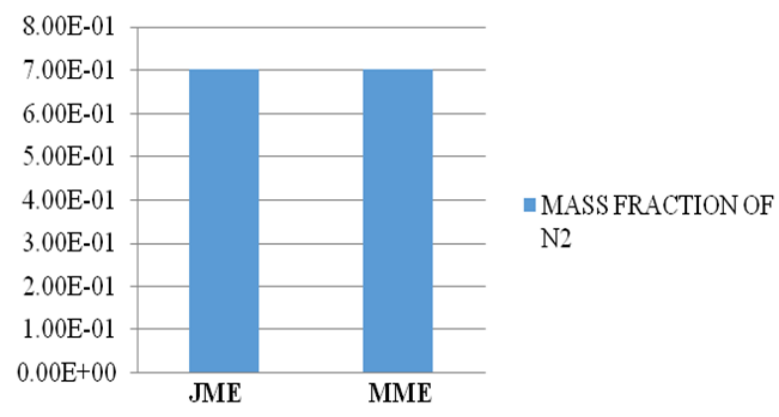

Figure 10. Values of mass fraction of $\mathrm{N}_{2}$ of combustion of JME and MME

\subsection{Mass fraction of $\mathrm{N}_{2}$ analysis}

The mass fraction of $\mathrm{N}_{2}$ is analysed for the Jatropha methyl ester blend and Mahua methyl ester blend using ANSYS Fluent. The mass fraction contours of nitrogen emission after combustion of JME and MME are analysed. The $\mathrm{N}_{2}$ emission is more or less similar for both JME and MME blends. The output graph is plotted with the values obtained from the above analysis of mass fraction contours of $\mathrm{N}_{2}$ of combustion of Jatropha Methyl Ester (JME) and Mahua Methyl Ester (MME) using Ansys Fluent as shown in Figure 10. From the overall comparison,Jatropha Methyl Ester (JME)biodiesel gives the same $\mathrm{N}_{2}$ emission compared to Mahua Methyl Ester (MME).

\subsection{Mass fraction contours of $\mathrm{H}_{2} \mathrm{O}$}

The mass fraction of $\mathrm{H}_{2} \mathrm{O}$ is analyzed with two different biodiesels i.e. Jatropha Methyl Ester (JME) and Mahua Methyl Ester (MME) as displayed in Figure 11. The analysis is done using Ansys software. The blue contour indicates the minimum value zone and the red contour indicates the maximum value zone.

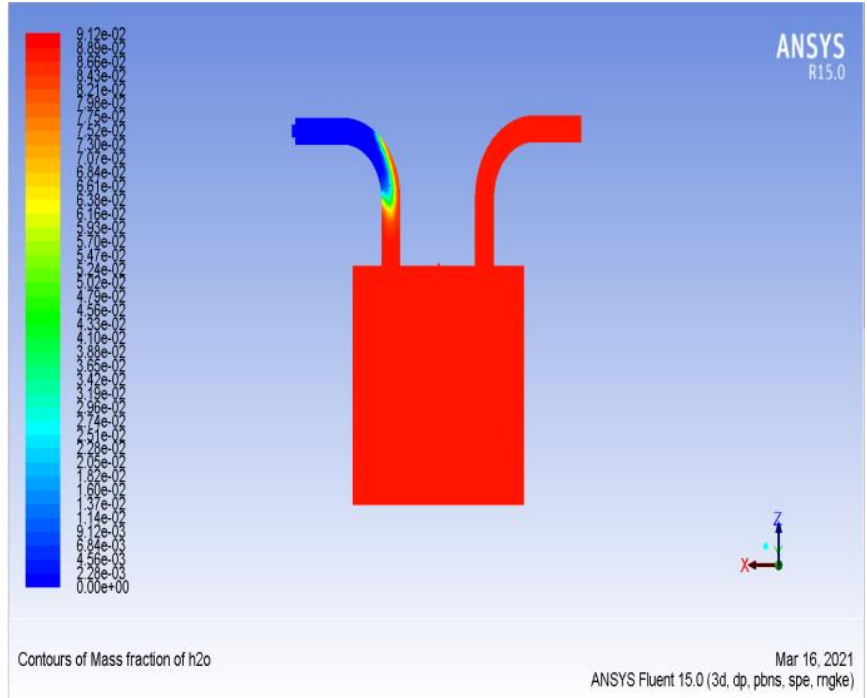

Figure 11. Mass fraction contours of $\mathrm{H}_{2} \mathrm{O}$ of combustion MME

The output graph is plotted as shown in Figure 12 with the values obtained from the above analysis of mass fraction contours of $\mathrm{H}_{2} \mathrm{O}$ of combustion of Jatropha Methyl Ester (JME) and Mahua Methyl Ester (MME) using Ansys Fluent. From the overall comparison,Jatropha Methyl Ester (JME)biodiesel gives the lower fraction of $\mathrm{H}_{2} \mathrm{Oemission}$ compared to Mahua Methyl Ester (MME).

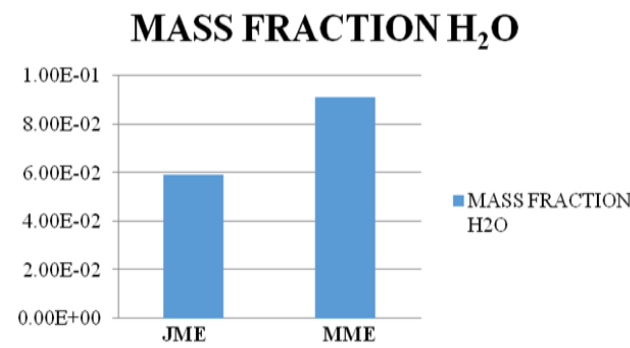

Figure 12. Values of mass fraction of $\mathrm{H}_{2} \mathrm{O}$ of combustion JME and MME 


\subsection{Mass fraction of $\mathrm{O}_{2}$ Analysis}

The mass fraction of $\mathrm{O}_{2}$ emission in CI Engine is analyzed with two different biodiesel i.e Jatropha Methyl Ester (JME) and Mahua Methyl Ester (MME).The analysis is done using Ansys softwareas displayed in Figure 13. The blue contour indicates the minimum value zone.Jatropha Methyl Ester (JME) and Mahua Methyl Ester (MME) gives similar values.

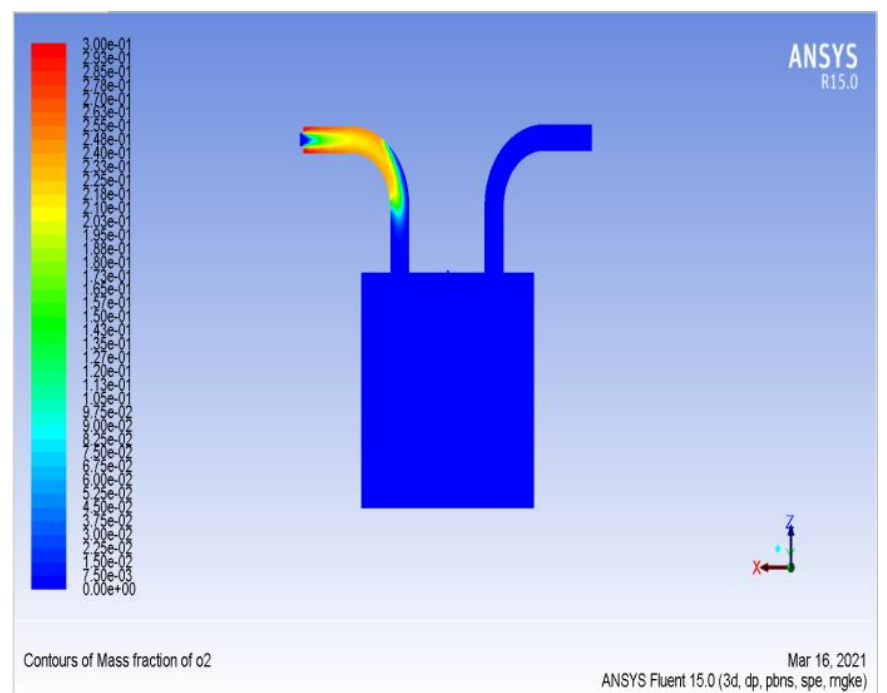

Figure 13. Mass fraction contours of $\mathrm{O}_{2}$ of combustion JME and MME

The output graph as displayed in Figure 14 is plotted with the values obtained from the above analysis of mass fraction contours of $\mathrm{O}_{2}$ of combustion of Jatropha Methyl Ester (JME) and Mahua Methyl Ester (MME) using Ansys Fluent. From the overall comparison,Jatropha Methyl Ester (JME)biodiesel gives the same $\mathrm{O}_{2}$ emission compared to Mahua Methyl Ester (MME).

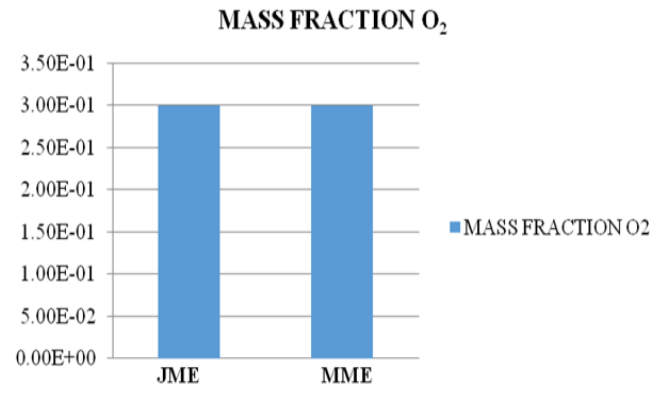

Figure 14. Values of mass fraction of $\mathrm{O}_{2}$ of combustion JME and MME

\section{CONCLUSION}

Effects of blends on alone chamber variable compression ratio diesel engine credits ride by double biodiesel blends B20 mixed extents (JME15MME5, JME10MME10, and JME5MME15) were effectively thought of. Coming up next are the goals from this assessment. Double Biodiesel blends in with 5\% Jatropha Methyl Ester (JME) oil, 15\% Mahua Methyl Ester (MME) oil, and $80 \%$ Diesel with more mixture squeezing element be able to be picked as a choice fuel. This work gives strong data to scholars to pick a sensible bio-diesel mix. This examination outfits measurable data about the introduction of the engine with hybridbio-diesel. Higher brake thermal efficiency and low BSFC, feweremissions are overwhelming assets of the picked dualbio-diesel mix. Nevertheless, the NOx ability toward be lessened by picking sensible advancement. Assessment of property of the biodiesel like Viscosity, calorific worth, urges the originators to pick the diverse blends of blends. Execution relationship of the blend in with C.I engine showed the biodiesel blend is the adequate unlimited basis to meet energy disaster and to statement the eco-obliging social issue. The assessment expands the data's base identifying with biodiesel. The CFD Analysis of Biodiesel done in two different biodiesel Jatropha Methyl Ester (JME) and Mahua Methyl Ester (MME) is used in the transport combustion model is used for this CFD Analysis, the CFD Results shows the Pressure, Temperature, and Pressure pattern inside the combustion chamber, volume fraction of the by-products during combustion is analyzed. From the overall comparison, Mahua Methyl Ester (MME) biodiesel blendgives the best results in combustion characteristics but in emission characteristics, Jatropha Methyl Ester (JME) gives better results.

\section{REFERENCES}

[1] Valente, O.S., da Silva, M.J., Pasa, V.M.D., Belchior, C.R.P., Sodre, J.R. (2010). Fuel consumption and emissions from a diesel power generator fuelled with castor oil and soybean biodiesel. Fuel, 89(12): 36373642. https://doi.org/10.1016/j.fuel.2010.07.041

[2] Kannan, G.R., Karvembu, R., Anand, R, (2011). Effect of metal-based additive on performance emission and combustion characteristics of diesel engine fuelled with biodiesel. Applied Energy, 88(11): 3694-3703. https://doi.org/10.1016/j.apenergy.2011.04.043

[3] Anand, R, Kannan, G.R., Rajasekhar Reddy, K., Velmath, S. (2009). The performance and emissions of a variable compression ratio diesel engine fuelled with bio-diesel from cotton seed oil. ARPN Journal of Engineering and Applied Sciences, 4(9): 72-87.

[4] Eknath, R.D., Ramchandra, J.S. (2014). Effect of compression ratio on energy and emission of VCR diesel engine fuelled with dual blends of biodiesel. Journal of Engineering Science and Technology, 9(5): 620-640.

[5] Hashimoto, N., Ozawa, Y., Mori, N., Yuri, I., Hisamatsu, T. (2008). Fundamental combustion characteristics of palm methyl ester (PME) as alternative fuel for gas turbines. $\quad$ Fuel, 87(15-16): 3373-3378. https://doi.org/10.1016/j.fuel.2008.06.005

[6] Kumbhar, S.R., Dange, H.M. (2014). Performance analysis of single cylinder diesel engine, using diesel blended with Thumba oil. International Journal of Soft Computing and Engineering (IJSCE), 4(1): 24-30. http://citeseerx.ist.psu.edu/viewdoc/download?doi=10.1 $.1 .651 .1083 \& \mathrm{rep}=\mathrm{rep} 1 \&$ type $=$ pdf.

[7] Silambarasan, R., Senthil, R, Pranesh, P., Mebin, S., Manimaran, M. (2015). Effect of compression ratio on performance and Emission characteristics of biodiesel blend operated with VCR engine. Journal of Chemical and Pharmaceutical Sciences, 5: 23-25.

[8] Venkateswara Rao, P. (2015). Compression ratio effect on Diesel Engine working with Biodiesel (JOME) Diesel blend as fuel. Research Journal of Chemical Sciences, 
http://www.isca.in/rjcs/Archives/v5/i7/9.ISCA-RJCS2015-095.pdf.

[9] Sureshkumar, K., Velraj, R., Ganesan, R. (2008). Performance and exhaust emission characteristics of a CI engine fueled with Pongamia pinnata methyl ester (PPME) and its blends with diesel. Renewable Energy, 33(10):

2294-2302 https://doi.org/10.1016/j.renene.2008.01.011

[10] Sivaganesan, S., Chandrasekaran, M., Ramasubramanian, S., Gnanavel, C. (2018). The influence of bio additive on the compression ignition engine with diesel and Jatropha methyl ester biodiesel. International Journal of Ambient Energy, 39(4) $377-381$ https://doi.org/10.1080/01430750.2017.1303643

[11] Murillo, S., Mrguez, J.L., Porteiro, J., Granada, E., Moran, J.C. (2007). Performance and exhaust emissions in the use of biodiesel in outboard diesel engines. Fuel, $86(12-13)$ :

$1765-1771$ https://doi.org/10.1016/j.fuel.2006.11.031

[12] Roger, A.K., Jo, J., Peterson, C.L. (1985). A rapid engine test to measure injector fouling in diesel engines using vegetable oil fuels. J. Am. Oil Chem. Soc., 62(11): 15631564. https://doi.org/10.1007/BF02541685

[13] Ryan, T.W., Dodge, L.G., Callahan, T.J. (1984). The effects of vegetable oil properties on injection and combustion in two different diesel engines. Journal of the American Oil Chemists Society, 61(10): 1610-1619. https://doi.org/10.1007/BF02541645

[14] Rewolinski, C., Shaffer, D.L. (1985). Sunflower oil diesel fuel: Lubrication system contamination. J. Am. Oil Chem. Soc., 61(7): 1120-1124. https://doi.org/10.1007/BF02542304

[15] Ziejewski, M., Kaufman, K.R. (1983). Laboratory endurance test of a sunflower oil blend in a diesel engine. Journal of the American Oil Chemists' Society, 60(8): 1567-1573. https://doi.org/10.1007/BF02666587

[16] Pryde, E.H. (1983). Vegetable oil as diesel fuels: Overview. Papers from the symposium on vegetable oils as diesel fuels. J. Am. Oil Chem. Soc., 60: 1557-1558. https://doi.org/10.1007/BF02666584

[17] Sureshkumar, K., Velraj, R., Ganesan, R. (2008). Performance and exhaust emission characteristics of a CI engine fueled with Pongamia pinnata methyl ester (PPME) and its blends with diesel. Renewable Energy, 33(10): 2294-2302. https://doi.org/10.1016/j.renene.2008.01.011

[18] Sivaganesan, S., Chandrasekaran, M., Ramasubramanian, S., Gnanavel, C. (2018). The influence of bio additive on the compression ignition engine with diesel and Jatropha methyl ester biodiesel. International Journal of Ambient $\begin{array}{llll}\text { Energy, } & 39 & \text { (4): } & 377-381\end{array}$ https://doi.org/10.1080/01430750.2017.1303643

[19] Murillo, S., Mrguez, J.L., Porteiro, J., Granada, E., Moran, J.C. (2007). Performance and exhaust emissions in the use of biodiesel in outboard diesel engines. Fuel,
86(12-13):

$1765-1771$

https://doi.org/10.1016/j.fuel.2006.11.031

[20] Niemi, S., Hätönen, T., Laiho, V. (1998). Results from a durability test of a mustard seed oil driven tractor engine. SAE Technical Paper 982528. https://doi.org/10.4271/982528

[21] Niemi, S., Illikainen, P., Mäkinen, M., Laiho, V. (1997). Performance and exhaust emissions of a tractor engine using mustard seed oil as fuel. SAE Technical Paper 970219. https://doi.org/10.4271/970219

[22] Radu, R., Mircea, Z. (1997). The use of sunflower oil in diesel engines. SAE Technical Paper 972979. https://doi.org/10.4271/972979

[23] Kannan, G.R., Karvembu, R., Anand, R. (2011). Effect of metal based additive on performance emission and combustion characteristics of diesel engine fuelled with biodiesel. Applied Energy, 88(11): 3694-3703. https://doi.org/10.1016/j.apenergy.2011.04.043

[24] Jayappa, K., Kumar, V., Purushotham, G. (2020). A review on mechanical and wear properties of ASTM a 494 M grade nickel-based alloy metal matrix composites, Materials Today: Proceedings, 37(3-4): 2027-2032. https://doi.org/10.1016/j.matpr.2020.07.499

[25] Jayappa, K., Kumar, V., Purushotham, G.G. (2021). Effect of reinforcements on mechanical properties of nickel alloy hybrid metal matrix composites processed by sand mold technique. Applied Science and Engineering $\quad$ Progress, 14(1): 44-51. https://doi.org/10.14416/j.asep.2020.11.001

[26] Graef, G., LaVallee, B.J., Tenopir, P., Tat, M., Schweiger, B., Kinney, A.J., Van Gerpen, J.H., Clemente, T.E. (2009). A high-oleic-acid and low-palmitic-acid soybean: agronomic performance and evaluation as a feedstock for biodiesel. Plant Biotechnology Journal, 7(5): 411-421. https://doi.org/10.1111/j.14677652.2009.00408.x

[27] Kumaraswamy, J., Kumar, V., Purushotham, G. (2021). Evaluation of the microstructure and thermal properties of (ASTM A 494 M grade) nickel alloy hybrid metal matrix composites processed by sand mold casting. International Journal of Ambient Energy, 42: 1-22. https://doi.org/10.1080/01430750.2021.1927836

[28] Khelge, S., Kumar, V., Shetty, V., Kumaraswamy J, (2021). Effect of reinforcement particles on the mechanical and wear properties of aluminium alloy composites: Review, Materials Today: Proceedings, pp. 1-9. https://doi.org/10.1016/j.matpr.2021.09.525

[29] Khelge, S., Kumar, V., Kumaraswamy, J. (2021). Optimization of wear properties on aluminum alloy (LM22) hybrid composite. Materials Today: Proceedings, pp. 1-8. https://doi.org/10.1016/j.matpr.2021.09.518

[30] Ramasubramanian, S., Kumar, S.S., Karikalan, L., Baskar, S. (2021). Performances emissions behaviors of Compression ignition engine by mahua oil. Materials Today: $\quad$ Proceedings, 37: 982-985. https://doi.org/10.1016/j.matpr.2020.06.187 